\title{
Height and body proportions in child abuse
}

\author{
J K H Wales, S M Herber, L S Taitz
}

\begin{abstract}
Abused children are said to retain 'infantile body proportions'. The presenting height, sitting height, and leg length standard deviation scores of 91 victims have been calculated from data derived from a study of local inner city schoolchildren. In the study population 31/91 (34\%) were significantly short and all but two of these had relatively shorter legs than backs, this limb disproportion being significant in 17 . In 25 patients of the original group followed up after various social interventions there was a significant recovery of leg length. Measurement of height and proportionality, especially when compared with appropriate modern or local standards, is an important means of detecting and following up victims of child abuse.
\end{abstract}

The impact of child abuse on growth is well recognised, ${ }^{1-4}$ and the victims are classically said to retain 'infantile body proportions', but this statement is largely based on anecdotal observations or small series. ${ }^{5-7}$ The present study was designed to look at the height and body proportions of an unselected sequence of children presenting to one of the authors (LST) in whom subsequent social and medical investigation showed unequivocal evidence of physical abuse and/or neglect. Some of the data on the height and weight of these children as well as the relationship of these measurements to social class, developmental delay at presentation, and recovery towards normal with various types of social intervention have been previously published. $^{8-10}$ In the course of the study the previously noted limitations of the current UK standards for analysis of sitting height and leg length again became manifest, 11 necessitating the use of proportionality standards derived from a local study of inner city schoolchildren. ${ }^{12}$

\section{Patients and methods}

Ninety one children with good medical and social evidence of physical abuse and/or neglect had measurements of height, sitting height, and derivation of leg length made by a single professional auxologist in the measurement laboratory of the Sheffield Children's Hospital. A Harpenden stadiometer and sitting height table (Holtain) were used to measure the children; the reliability of measurement of a single child using this equipment, methodology, and auxologist has previously been published. ${ }^{13} \quad 14$

In order to allow comparison of children of different ages and sex, a standard deviation (SD) score was calculated for each value using data derived from a study of 345 local children ${ }^{12}$ to calculate sitting height and leg length SD score. Although the height standards derived from the Tanner and Whitehouse data are still broadly applicable to the current UK population, the 1978 data on sitting height and leg length ${ }^{15}$ shows a major, relatively fixed, discrepancy when compared with present day populations in that children have longer legs and shorter backs than would be anticipated from the use of the Tanner and Whitehouse standards. ${ }^{11} 12$ The local data on a relatively small population was used because of the similarities of social class and other demographic data to the abused group, but has been validated in a larger study of 2965 children with a broader population $\mathrm{mix}^{16}$ and is also strikingly similar to modern European data. ${ }^{17}$ In a normally distributed population the SD score will have a mean of zero and a SD of one. SD scores of -2 to +2 will include $95.44 \%$ of the population.

The group consisted of 52 boys and 39 girls with an age range of 0.2 to 13.2 years; the age distribution was appreciably skewed to the younger ages (median age 2.5 years), and the sex and age distribution reflects that of a previously published study by Baldwin and Oliver. ${ }^{18}$

The employment category of the parent(s) is shown in fig 1. Demographical information on the social class and unemployment rates (but not the single parent family rates), of the electoral wards in 1986 from which the normative local measurements were collected is available and shows a $19 \cdot 5 \%$ unemployment rate and $25 \%$ of the population in social classes IV and V. There is therefore an apparent over representation of unemployed parents, even compared with high local rates, in the abuse

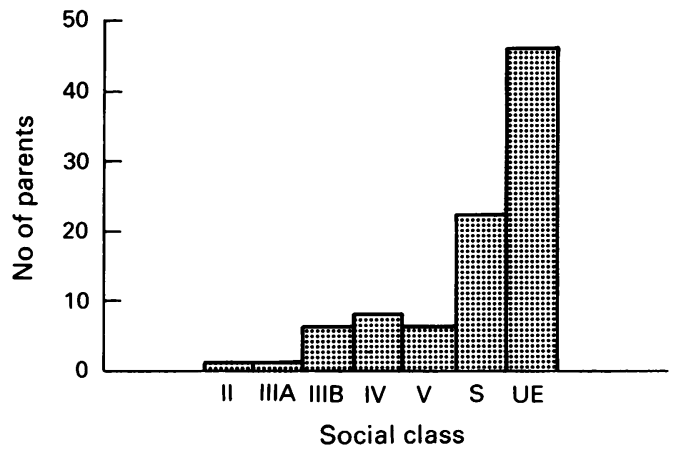

Figure I Employment category of the parent $(s)$ of the abused children. (S, single parents; UE, unemployed). 
group and also a very large number of single parents. This distribution has previously been described and discussed. ${ }^{19} 20$

As physical abuse may on occasion be a 'spur of the moment' event, and neglect by its very nature long term, the patients were subdivided into two groups, one of 57 children with physical abuse and another of 34 deprived children with no known physical injury, to determine if there was any difference in body habitus. In addition, 25 patients were seen for follow up measurements at one to four years after presentation.

\section{Results}

Figure 2 shows the results of a local study ${ }^{12}$ measuring the height and sitting height of 345 children from inner city Sheffield superimposed on the current UK charts of Tanner and Whitehouse. ${ }^{15}$ It can be seen that although there is a tendency for 'modern' children to be very slightly taller than their predecessors, a major discrepancy is seen in relation to body proportions, with the study group having consistently longer legs and shorter backs.

To analyse the data to show the effects of abuse on individuals, a scattergram of sitting height SD score has been plotted against leg length SD score as illustrated in fig 3. This means of demonstrating the data shows individuals with normal stature falling within the central stippled box. Furthermore, disproportion can be represented by the perpendicular distance from a 'line of perfect proportion' (where sitting height SD score=leg length SD score) drawn through the intercept.

Figure 4 shows that $31 / 91$ abused or deprived children were found to be short $(\mathrm{p}=<0.001)$; $(17 / 57$ and $14 / 34 ; 30$ and $41 \%$ respectively (not significant) in the two subgroups). All but two of these children showed leg length disproportion. The significance disproportion can be estimated by the method described by Young $e t$
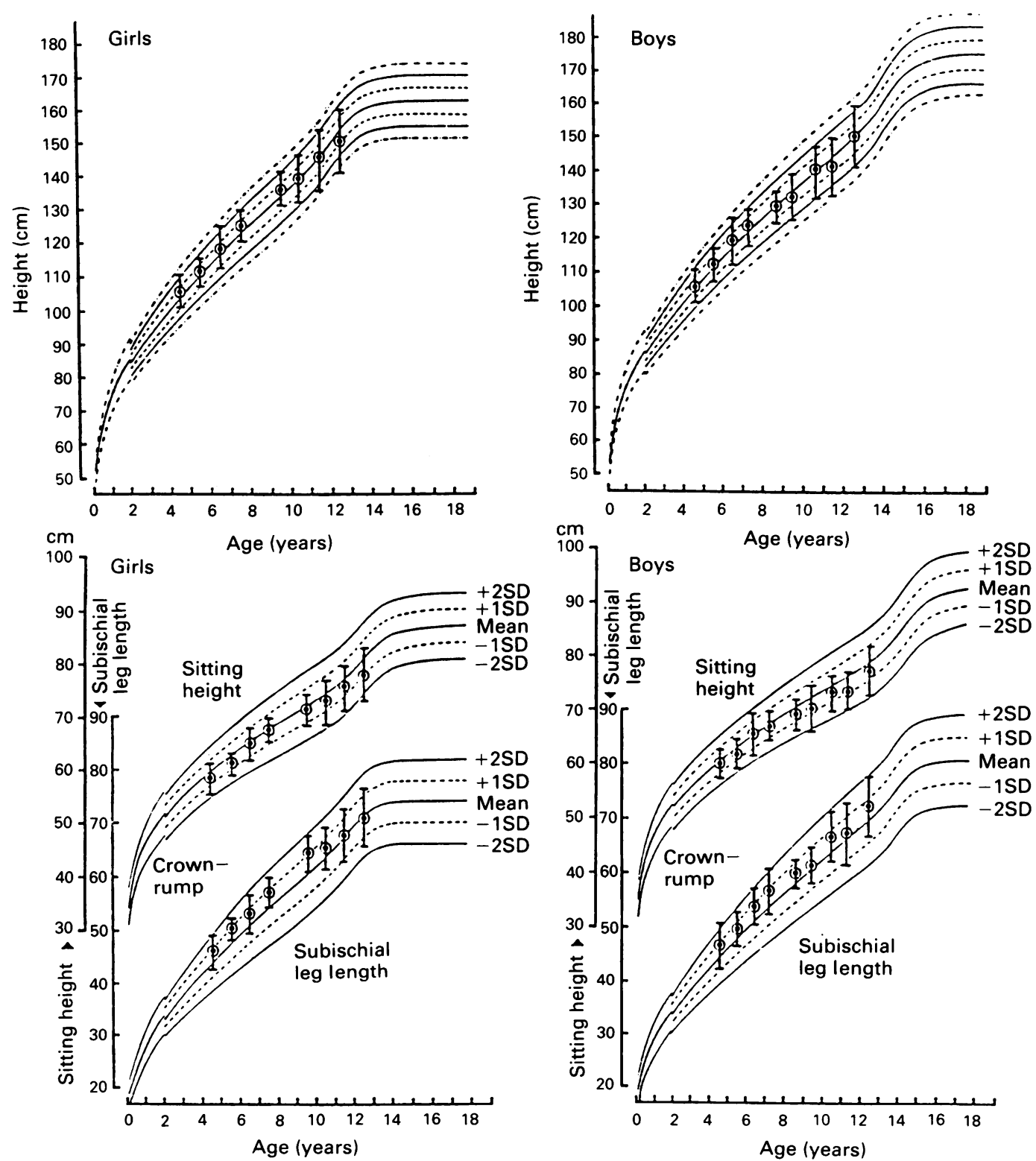

Figure 2 Mean $(S D)$ heights, sitting heights, and subischial leg lengths of 345 inner city Sheffield schoolchildren plotted on conventional UK charts. 


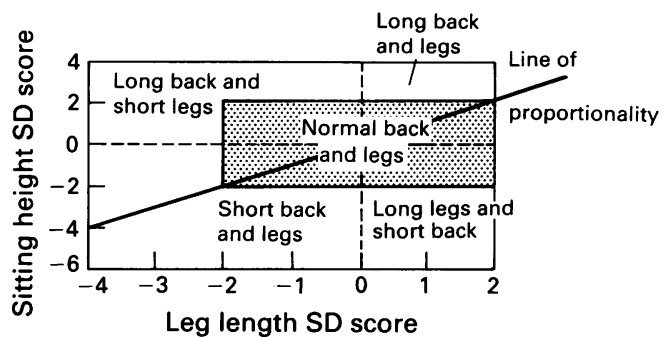

Figure 3 Demonstration of the scattergram used to represent the height and proportionality of individuals in the study.
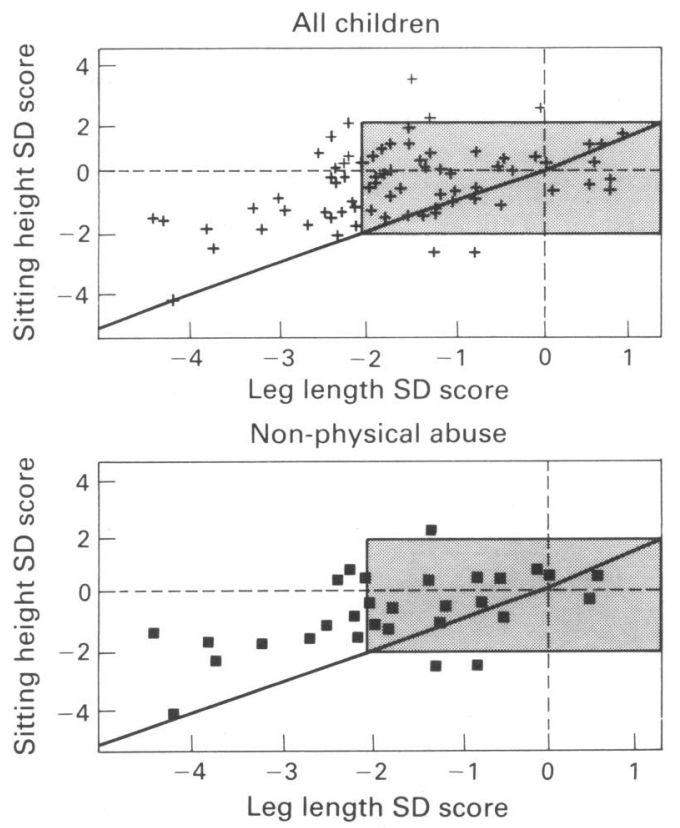

Physical abuse

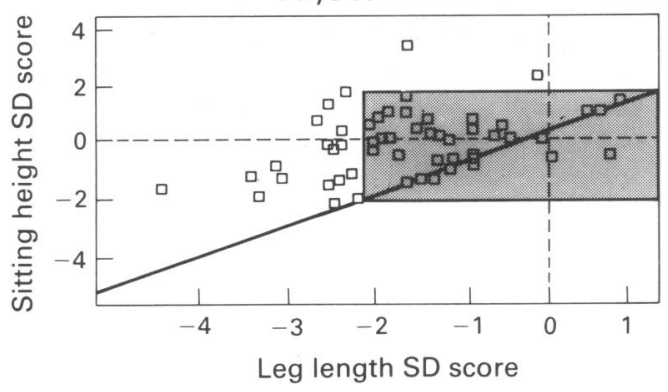

Figure 4 Scattergram of sitting height SD score against leg length $S D$ score calculated from modern local data. Normal stature is encompassed in the central shaded area and the 'line of perfect proportion' is drawn through the intercept. Upper/lower segment disproportion is thus indicated by the perpendicular distance from this line.

$a l .^{21}$ By subtracting the leg length SD score from the sitting height SD score, values of more than \pm 2 SD can be taken to represent statistically significant disproportion as shown in fig 5 where 17 children show significant shortening of the limbs compared with the back.

The group as a whole showed an appreciable skewing to the lower social classes and unemployed and single parents. This may represent a real phenomenon or a difference in ascertainment of cases but is probably a combination of both factors. Shorter leg length may in itself be associated with lower social class ${ }^{22}$ and a secular increase of leg length occurs with improving social circumstances. ${ }^{23}$ To exclude the difference in proportionality being due to social class effects, rather than being truly secondary to abuse, leg length SD score was related to three broad social categories (non-manual, $\mathrm{n}=8$; manual, $\mathrm{n}=14$; unemployed and single parent, $n=69$ ). Although the numbers in the higher social class groups were small there was a tendency for the shortest legs to be seen in the higher social class abused children (fig 6), making the observed disproportion unlikely to be due to social class effects alone.

The table shows the SD score at follow up in 25 patients (a mixture of the two subgroups), from one to five years after presentation and after a variety of social interventions, ranging from adoption and long term fostering to home care with social work supervision. There is a tendency for all values to 'recover' towards the mean, but this only reaches statistical significance for leg length. There was no apparent relationship between the initial degree of stunting and subsequent 'catch up' growth.

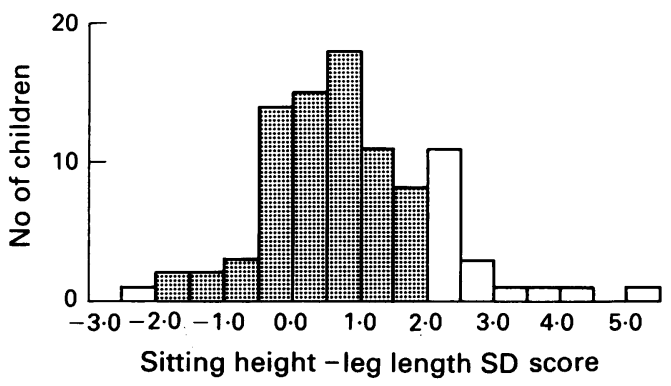

Figure 5 Leg length SD score subtracted from sitting height $S D$ score. Significant disproportion is represented by the unshaded columns.

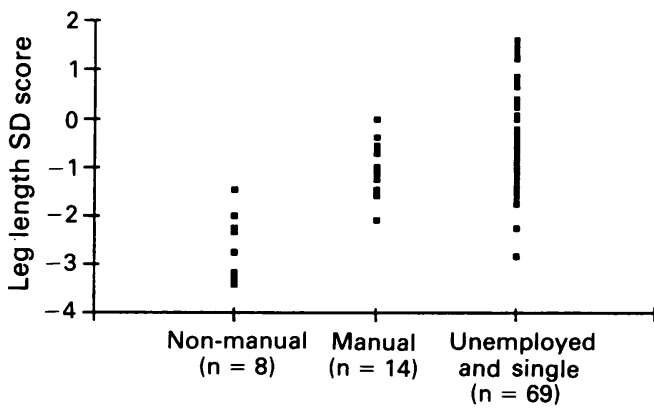

Social class

Figure 6 Leg length SD score plotted against three broad divisions of social class.

Height $(H t)$, sitting height $(S H)$, and leg length $(L L)$ $S D$ scores at presentation and follow up $(H t 2, S H 2, L L 2)$ of 25 children

\begin{tabular}{|c|c|c|c|}
\hline & Range & Mean & $S D$ scores \\
\hline $\begin{array}{l}\mathrm{Ht} \\
\mathrm{SH} \\
\mathrm{LL}\end{array}$ & $\begin{array}{l}-4.3 \text { to }-0.1 \\
-4.7 \text { to }+0.6 \\
-3.4 \text { to }+0.3\end{array}$ & $\begin{array}{l}-1.6 \\
-1.5 \\
-1.3\end{array}$ & $\begin{array}{l}1 \cdot 1 \\
1 \cdot 2 \\
1 \cdot 1\end{array}$ \\
\hline $\begin{array}{l}\mathrm{H}+2 \\
\mathrm{SH} 2 \\
\mathrm{LL} 2\end{array}$ & $\begin{array}{l}-2.6 \text { to }-0.1 \\
-2.9 \text { to }+0.7 \\
-2.6 \text { to }+0.2\end{array}$ & $\begin{array}{l}-1 \cdot 2 \\
-1 \cdot 1 \\
-0.9\end{array}$ & $\begin{array}{l}0.8 \\
0.9 \\
0.7\end{array}$ \\
\hline
\end{tabular}




\section{Discussion}

There can be no doubt that physical abuse and neglect of children leads to short stature and failure to thrive. The correlation of speech and developmental delay with shortness leads to the conclusion that both are manifestations of long term unhappiness and disruption within the family. ${ }^{9}$ The short, abused, children will show a recovery of growth with the more radical changes in the home circumstances and this can be used to gauge the success of any intervention. ${ }^{8}$ Children can also show catch-up growth from within the normal centile range to a higher centile channel on removal from the abnormal environment, demonstrating that they have not been achieving their full growth potential ${ }^{10}$; although growth screening programmes might lead to the identification of some cases of 'non-organic failure to grow', some children would escape detection.

We have demonstrated that a significant proportion of abused children are short and that lower limb disproportion is a frequent finding. As control of the growth of the long bones is largely mediated by growth hormone and growth hormone dependent growth factors, the lower leg stunting shown in these children, and the recovery with social work intervention, adds weight to the proposition that this poor growth is due to reversible undersecretion of growth hormone. $^{24-26}$ One could postulate that a combination of emotional and environmental factors, possibly with chronic sleep disturbance, act through the hypothalamus to decrease nocturnal growth hormone release. Suboptimal nutrition could also further modify growth factor action in the periphery.

Our thanks to Mrs M Pickering, auxologist; Dr D Skuse, Institute of Child Health, for his helpful comments and knowledge of the literature; and Mrs M Kessel, principal social worker, Sheffield Children's Hospital.

1 Silver HK, Finkelstein M. Deprivation dwarfism. $\mathcal{F}$ Pediat 1967;317:317-24.

2 Powell GF, Brasel JA, Blizzard RM. Emotional deprivation and growth retardation simulating idiopathic hypopitui- tarism. I. Clinical evaluation of the syndrome. $N$ Engl $\mathcal{f}$ Med 1967;276:1271-8.

3 Money J. The syndrome of abuse dwarfism (psychosocial dwarfism or reversible hyposomatotropism). Am $\mathcal{J}$ Dis Child 1977;131:508-13.

4 Lynch MA, Roberts J. The children's growth. In: Lynch MA, Roberts J, eds. Consequences of child abuse. London: Academic Press, 1982:48-59.

5 Skuse DH. Emotional abuse and delay in growth. The ABC of child abuse. $B M \mathcal{F}$ 1989;299:113-5.

6 MacCarthy D. The effects of emotional disturbance and deprivation on somatic growth. In: Davis JA, Dobbing J, eds. Scientific foundations. Paediatrics. 2nd Ed. London: Heinemann Medical Books, 1981:54-73.

7 Hopwood NJ, Becker DJ. Psychosocial dwarfism: detection, evaluation and management. Child Abuse Negl 1979;3: 439-47.

8 King JM, Taitz LS. Catch up growth following abuse. Arch Dis Child 1985;60:1152-4.

9 Taitz LS, King JM. A profile of abuse. Arch Dis Child 1988;63:1026-31.

10 Taitz LS, King JM. Growth patterns in child abuse. Acta Paediatr Scand [Suppl] 1988;343:62-72.

11 Herber SM, Milner RDG. Sitting heights in Sheffield 1985: have standards changed? Acta Paediatr Scand 1987;76: 818-23.

12 Herber SM. The effect of malignant disease on growth in childhood. Witwatersrand: University of Witwatersrand, 1986. (PhD thesis.)

13 Wales JKH, Milner RDG. Knemometry in assessment of linear growth. Arch Dis Child 1987;62:166-71.

14 Wales $\mathrm{JKH}$. The assessment and application of knemometry. Oxford: University of Oxford, 1990. (DM thesis.)

15 Tanner JM, Whitehouse RH. Standards for sitting height and sub-ischial leg length from birth to maturity: British children,

16 Shirley A. The construction and analysis of growth curves for children. Sheffield: University of Sheffield, 1987. (MSc
(Morley A. The construction and analysis of growth curves for children.

17 Prader A, Budlinger H. Korpermasse, wachtstumgeschwindigkeit und knochenaller gesunder kinder in der ersten zwolf jahren (longitudinale wachstumsstudie Zurich). Helv Paediatr Acta [Suppl] 1977;37:1-44.

18 Baldwin JA, Oliver JE. Epidemiology and family characteristics of severely-abused children. Br $\mathcal{J}$ Prevent Soc Med 1975;29:205-21.

19 Taitz LS. Child abuse: some myths and shibboleths. Hosp Update 1991:17:400-8.

20 Taitz LS, King JM, Nicholson J, Kessel M. Unemployment and child abuse. BMF 1987;294:1074-6.

21 Young MC, Ribeiro J, Hughes IA. Growth and body proportions in congenital adrenal hyperplasia. Arch Dis Child 1989;64:1554-8.

22 Billewicz WZ, Thomson AM, Fellowes HM. A longitudinal study of growth in Newcastle upon Tyne adolescents. Ann Hum Biol 1983;10:125-33.

23 Tanner JM, Hayashi T, Preece MA, Cameron N. Increase in length of leg relative to trunk in Japanese children and length of leg relative to trunk in Japanese children and
adults from 1957 to 1977: comparison with British and with adults from 1957 to 1977: comparison with British and

24 Powell GF, Brasel JA, Raiti S, Blizzard RM. Emotional deprivation and growth retardation simulating idiopathic hypopituitarism. II. Endocrinologic evaluation of the syndrome. N EnglF Med 1967;276:1279-83.

25 Neufeld ND. Endocrine abnormalities associated with deprivation dwarfism and anorexia nervosa. Pediatr Clin North Am 1979;26:199-208.

26 Green WH, Campbell M, David R. Psychosocial dwarfism: a critical review of the evidence. F Am Acad Child Psychiatry 1984;23:39-48. 